\title{
Museus, patrimônio e poder: reflexões sobre as práticas de memória na modernidade
}

\author{
Museums, heritage, and power: reflections on the \\ practices of memory in modernity
}

\author{
Kátia Lerner \\ Pesquisadora do Centro de Informação Científica e Tecnológica, (CICT/Fiocruz) \\ Doutora em Antropologia Social pelo IFCS/UFRJ \\ Rua Senador Euzebio 40/404 \\ 22250-080 Rio de Janeiro - RJ - Brasil \\ klerner@cict.fiocruz.br
}

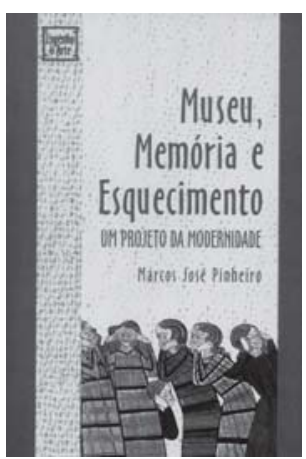

Pinheiro, Marcos José. Museu, memória e esquecimento: um projeto da modernidade. Rio de Janeiro: E-Papers, 2004. 262 p. \useu, memória e esquecimento: um projeto da modernidade é um livro que provoca reflexões sobre um tema bastante atual: a forte presença das práticas mnemônicas nas modernas sociedades ocidentais. Originalmente apresentado como uma dissertação de mestrado na área de engenharia de produção na Coppe/UFRJ em 2002, esse trabalho nasceu das reflexões de Marcos José Pinheiro sobre suas atividades na área de memória e patrimônio. $\mathrm{O}$ autor aponta como sua maior motivação a insatisfação com o modo como eram tratados os patrimônios culturais, o que, no seu entender, parecia reproduzir as relações de exclusão, dominação e homogeneização presentes na sociedade contemporânea. Isto se traduziria, por exemplo, pelo caráter elitista do museu, que privilegiaria a educação e a difusão de saberes a uma faixa privilegiada da população, pela sua distância em relação aos símbolos culturais e à memória social das camadas mais carentes da população, bem como pela sua imbricação com o atual modelo político e econômico mundial do neoliberalismo e da globalização. Nesse sentido, o autor desde logo manifesta sua escolha por um tipo de preservação que esteja associado à defesa da valorização da diversidade cultural.

Para dar conta dessas inquietações, Pinheiro realiza um longo e denso percurso pelas idéias de autores que abordam os temas da memória, dos museus e do contexto contemporâneo. Seu ponto de partida é um comentário de Andréas Huyssen: diferente das sociedades tradicionais, a modernidade é impensável sem um projeto museico e, portanto, o museu é eminentemente um projeto da modernidade. Esta será uma idéia-chave na sua reflexão e norteará a própria estrutura do texto. Dividido em duas grandes partes, a primeira, intitulada "Das memórias, sua seleção e institucionalização", aborda em seu primeiro capítulo o tema "Modernidades e museus". Nele, Pinheiro se lança no esforço de qualificar melhor o conceito de modernidade com o qual está trabalhando e, para tal, privilegia dois autores: Henrique de Lima Vaz e Max Weber. De Lima Vaz utiliza o conceito de 'modernidade pós-cristã', o qual expressa um momento na Humanidade em que se processou uma ruptura com o eixo teológico, resultando na reorganização do sistema simbólico da civilização ocidental. Nessa mesma linha cita Weber e suas reflexões sobre o processo de desencantamento do mundo e do predomínio de uma lógica burocrática e impessoal, chamando a atenção para seus impactos sobre o poder até então exercido pelas religiões no mundo ocidental, o que pro- 
moveu a auto-representação do homem enquanto ser de grande força frente à natureza e à sociedade. $\mathrm{O}$ autor alega que, nesta nova perspectiva, o homem pode ser definido como 'um ser capaz de ação'; é esse o gancho para Pinheiro começar a explicitar as estreitas relações entre a modernidade e a cultura dos museus, o que se dá quando ele diz que tal ação é norteada e estimulada pela imagem, transformando-a (a ação) cada vez mais em especulação, tornando a cultura mais visual e o indivíduo um mero espectador.

Essa correlação será explorada mais detalhadamente no item seguinte, no qual o autor acompanha o surgimento do museu moderno, destacando quatro características que ilustram suas afinidades com a modernidade. A primeira delas era a concretização pelos museus de algumas das premissas básicas estabelecidas pelo Iluminismo, ligadas à democratização do saber e à difusão e educação da cultura culta. Essas características acabariam por desempenhar um papel de ratificação da hegemonia da cultura ocidental, tanto na arte como na ciência, sobre o Ocidente e o resto do mundo, omitindo outras formas de saber e estética diferentes dos padrões cartesianos e evolucionistas.

A segunda grande característica apontada pelo autor retoma a idéia do museu enquanto espaço de consagração da cultura visual. Ele diz que esse processo gerou a transformação das massas em público, e que o museu teria passado a assumir uma função mediadora entre diferentes instâncias, seja entre a cultura e o mercado seja entre as culturas culta, popular e de massa. Mais ainda, sua estratégia de exibição dos objetos dispondo-os de forma isolada de seu contexto histórico, cultural, social e econômico acabava por estetizá-los, contribuindo para sancionar a estética como esfera de valor e dominação.

A terceira e a quarta características são apenas brevemente mencionadas nesse capítulo. Trata-se da transformação do museu no grande lugar metafórico das representações da memória, contribuindo para a criação de uma 'cultura museica'. E, por fim, da força do museu enquanto lugar de construção do espírito do nacionalismo e da cultura nacional em detrimento das culturas populares, o que acabou por tornálo lugar de gestação das formas de dominação e legitimador de ações imperialistas e dominadoras.

No segundo capítulo, "A crise da memória e a musealização", Pinheiro busca refletir sobre os processos de memória e esquecimento, entendidos como duas instâncias profundamente interligadas e pensando-os historicamente. $\mathrm{O}$ autor ressalta que, em contraponto à ênfase no futuro, característica do momento inicial da modernidade pós-cristã, houve uma mudança de percepção temporal a partir da década de 1980, quando o Ocidente passou a atribuir maior valor ao passado, o que se expressava pelo desejo de recordação total. Entre os motivos que justificam esse processo, o autor sugere cinco possíveis respostas. A primeira seria uma tentativa de recuperar as possibilidades não realizadas como propiciadoras de um futuro mais atraente; a segunda seria a volta de passados não resolvidos, sem luto, ligados a processos políticos dolorosos; a terceira seria uma tentativa de reinterpretar o passado, representando uma desfiguração da memória; a quarta seria motivada pela conscientização do homem de seu atual poder de interferir na mortali- 
dade da natureza, o que o levaria a uma maior necessidade de armazenamento da memória como forma de se perpetuar. E, por fim, Pinheiro cita a crise na estrutura das temporalidades, gerada pela velocidade cada vez maior das sociedades contemporâneas, com a aceleração das imagens e das informações da mídia. Isto estaria trazendo o passado para o presente e criando um sentido de simultaneidade temporal e espacial, com um permanente sentimento de defasagem e dando a sensação de um presente cada vez mais efêmero. Daí a busca ansiosa por reter e preservar o passado.

Qual seria, nesse cenário, o papel do museu? Surgido como um projeto de e para a elite, o museu foi se tornando alvo de intensos ataques, a ponto de se prever sua falência como instituição no início do século XX. Entretanto, esse processo foi revertido a partir da década de 1980 quando, ao invés de ser visto como o espaço de uma cultura transcendente, encarnação da 'civilização', passou a ser considerado lugar de representação das diferenças e dos conflitos entre diversas culturas; mudou assim suas formas de representação, ampliou seu público e diversificou seus formatos. Junto com isso surgiram novas facetas, como uma dimensão marcadamente espetacular e sua ligação com o comércio e o entretenimento.

O terceiro e último capítulo chama-se "Memória, nacionalismo e cultura" e busca desenvolver as relações antes anunciadas entre esses três elementos. Pinheiro relembra que o processo de constituição do estado nacional acarretou um alargamento de seu poder sobre os cidadãos, expresso, entre outras coisas, pela educação e comunicação. Isto se tornou crucial na homogeneização da população, atingindo diretamente o âmbito da cultura e a constituição do nacionalismo. Neste sentido o museu ocupou um lugar de destaque na consolidação da identidade nacional, como atesta o papel do Louvre e do British Museum em seus países. Entretanto, mais do que apenas serem fruto deste novo momento, acabaram por ratificar alguns de seus aspectos mais nocivos, como o colonialismo e o imperialismo. Mesmo internamente o museu teria ajudado a corroborar uma perspectiva de dominação na medida em que, exaltando os feitos e a glória da nação, estava contribuindo para o processo de repressão das culturas regionais em nome de uma identidade coletiva mais ampla.

Isto se estenderia a um contexto posterior, o da mundialização da cultura, em que a nação não é mais o principal referencial de identidade. Pinheiro argumenta que a memória internacional popular trouxe um esquecimento mais intenso que o da memória local ou nacional, em razão da quantidade maior de conflitos e da necessidade de consensos. Tais práticas mnemônicas acabaram por reforçar determinados aspectos da globalização, como o acirramento das diferenças sócio-econômicas e a homogeneização dos hábitos, necessidades e desejos, em um contexto em que, se por um lado a cultura atinge um número maior de pessoas, por outro está menos exposta à crítica.

Na segunda parte do livro, intitulada "Os caminhos da musealização", o autor se aprofunda em alguns debates sobre a cultura da memória na atualidade. No primeiro capítulo, "Modelos explicativos para a atual cultura dos museus", explora uma sugestão de Andréas Huyssen sobre as idéias de filósofos que abordam o tema, trazendo em especial 
três vertentes. Começa citando os alemães Hermann Lübbe e Odo Marquard e seu argumento segundo o qual, diante da nova experiência espaço-temporal fomentada pelas novas tecnologias, onde o presente rapidamente se torna obsoleto, o homem estaria cada vez mais se voltando para o passado como uma espécie de compensação. Pinheiro dá continuidade a esse tema citando David Harvey: em sociedades cujo modelo de produção gera uma sensibilidade baseada no descartável e instantâneo, seriam produzidas ações e condutas que visam solidificar algum contexto estável, seja através da religião, de lideranças políticas carismáticas, instituições representadas pelo ethos familiar e comunitário. Pinheiro alerta para os perigos desse tipo de teoria compensatória, cujo teor nostálgico pode gerar alienação da realidade e cuja ênfase no passado pode ser um canal de expressão para o nacionalismo extremista.

A segunda vertente se refere às idéias de Jean Baudrillard e Henri Pierre Jeudi. Estes autores caracterizam o museu como uma 'máquina de simulação' que em nada se diferencia de outros meios de divulgação da cultura de massa. A despeito dos limites desta avaliação tão pessimista, Pinheiro busca aproveitar algumas de suas possibilidades reflexivas, utilizando-as como mecanismos de 'alerta'. Citando especialmente Baudrillard, recupera a idéia crítica do museu como uma instituição que preserva a memória reconstituindo um passado que não (mais) existe - daí a idéia de simulação - e ao mesmo tempo promove o esquecimento do presente vivo, do objeto real e espontâneo, de seus mecanismos de controle e dominação. O passado sofreria uma espécie de 'revisionismo' o qual, ao inventariar os atos pretéritos, apagaria da memória os conflitos e aspectos negativos e promoveria a possibilidade de refúgio em um passado sem máculas.

Por fim, o autor aborda o terceiro modelo citado por Huyssen, desenvolvido pelo jornal Ästhestik und Kommunikation, de Berlim. Segundo esta vertente, o crescimento dos museus estaria em ligação direta com a experiência midiática contemporânea. Em meio a tanta simulação o objeto museico ofereceria a possibilidade de experiências reais ou de materialidade física, assim como representaria um espaço de autenticidade, um contraponto à experiência televisiva; daí se explicar o enorme interesse por parte do público. Embora concorde em vários aspectos com tais idéias, Pinheiro alerta para sua dimensão conformista, que acaba por ser acrítica à sociedade de consumo e à cooptação do museu dentro dessa lógica.

O autor aborda ainda uma quarta perspectiva, a de Guy Debord, que assinala como marca das sociedades contemporâneas a estreita relação entre tecnologia/meios de comunicação de massa e passividade. Pinheiro buscará aplicar esse conjunto de idéias na análise dos museus contemporâneos e, citando a interatividade dos museus de ciências, aponta como isso produz uma ilusão de participação que, na prática, induz ao imobilismo, promovendo a cooptação de mais agregados a um sistema capitalista tecnicista cuja liderança tecnológica está em jogo. $\mathrm{O}$ mesmo pode ser dito quanto às exposições de arte e de centros de ciências ao exporem o que ele designa como 'objetos sem valor cultural'. Isso, segundo Pinheiro, não é percebido pelo público, que não teria muita capacidade crítica diante dessas classificações. Todos esses 
casos seriam exemplos da sociedade espetacular, que promove a manipulação da cultura, e das instituições culturais e técnico-científicas, as quais mantêm e consolidam a ordem dominante.

No último capítulo, Pinheiro traz mais uma vez a crítica às formas de utilização das conquistas tecnológicas nas sociedades contemporâneas através das idéias de I. Illich. Segundo esse autor, as mesmas ferramentas que permitiram ao homem contemporâneo assumir o controle do tempo e do espaço teriam acabado por aprisioná-lo. Propõe, então, a instauração de um novo modelo de relação com o outro e o meio ambiente, que chama de 'convivencial', pautado pelo valor ético, de preservação da diversidade de modos e costumes de vida.

Pinheiro aproveita as palavras de Illich para encerrar o livro e propor a intensificação do potencial dos museus enquanto modelos de ferramentas convivenciais. Em sua visão, os museus de ciência, ao terem como missão a difusão e popularização da ciência e da tecnologia, realizam a tarefa de tornar tais saberes mais accessíveis ao público e, conseqüentemente, desarticulam o monopólio de saberes e a especialização acelerada. No caso dos museus de arte e cultura, eles permitem auto-reflexão e familiarização com a alteridade, possibilitando a preservação de costumes e saberes tradicionais. Pinheiro acredita que, agindo de forma crítica e dialética, o museu estará confirmando e recuperando as bases que constituíram a própria modernidade, ou seja, a razão crítica e a reflexão das contradições, contribuindo para a instauração de uma nova modernidade.

Como se pode ver, o livro de Pinheiro revela-se um cuidadoso e denso trabalho de articulação entre diferentes teorias. Entre seus méritos cabe destacar a desnaturalização que ele promove sobre o tema da memória e as pistas que oferece ao leitor para compreender a forte presença das práticas mnemônicas nas sociedades contemporâneas. Mais do que uma suposta 'amnésia' anterior, o que estaria em jogo seria uma nova percepção da memória, uma nova atribuição social que as sociedades contemporâneas estariam outorgando às atividades mnemotécnicas.

Um outro dado a ser destacado no livro é o tom crítico que o autor imprime ao texto, marcando de forma evidente seu posicionamento nesse campo de atuação. Se tal postura é interessante na medida em que interpela o leitor a um posicionamento mais questionador sobre as práticas de preservação histórica e cultural, em alguns momentos sua demasiada ênfase no museu enquanto ratificação da ordem hegemônica o distancia da análise das inúmeras experiências de desafio a essa mesma ordem. Seria interessante explorar suas implicações e em que medida elas também dialogam com os pressupostos da modernidade. Isso poderia enriquecer sobremaneira a análise dos mecanismos de controle que ele tão pertinentemente aponta, revelando que estão em jogo diferentes concepções de poder, de memória e de patrimônio, tanto no interior dos grupos 'dominantes' como no dos 'minoritários'.

De todo modo, estes comentários apenas ilustram a riqueza de questões que o texto suscita, representando um instigante convite à reflexão para pesquisadores, profissionais da área de patrimônio, e para aqueles simplesmente interessados em melhor compreender as práticas de memória nas sociedades contemporâneas. 


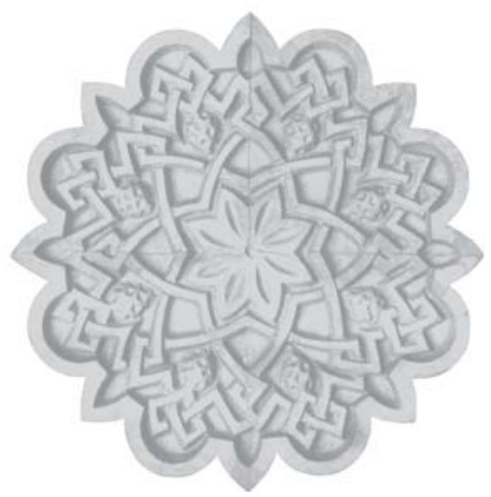

